\title{
Confinement of Reinforced-Concrete Columns with Non- Code Compliant Confining Reinforcement plus Supplemental Pen-Binder
}

\author{
Anang Kristianto ${ }^{1}$, Iswandi Imran ${ }^{2}$, Made Suarjana ${ }^{2}$ \& Ivindra Pane ${ }^{2}$ \\ ${ }^{1}$ Department of Civil Engineering, Maranatha Christian University, \\ Jalan Suria Sumantri 65, Bandung 40164, Indonesia \\ ${ }^{2}$ Department of Civil Engineering, Bandung Institute of Technology, \\ Jalan Ganesha 10, Bandung 40132, Indonesia \\ Email: anang.kristianto@gmail.com
}

\begin{abstract}
One of the important requirements for earthquake resistant building related to confinement is the use of seismic hooks in the hoop or confining reinforcement of reinforced-concrete column elements. However, installation of a confining reinforcement with a 135-degree hook is not easy. Therefore, in practice, many construction workers apply a confining reinforcement with a 90degreehook (non-code compliant). Based on research and records of recent earthquakes in Indonesia, the use of a non-code compliant confining reinforcement for concrete columns produces structures with poor seismic performance. This paper presents a study that introduces an additional element that is expected to improve the effectiveness of concrete columns confined with a non-code compliant confining reinforcement. The additional element, named a pen-binder, is used to keep the non-code compliant confining reinforcement in place. The effectiveness of this element under pure axial concentric loading was investigatedcomprehensively. The specimens tested in this study were 18 concrete columns, with a cross-section of $170 \mathrm{~mm} \times 170 \mathrm{~mm}$ and a height of 480 $\mathrm{mm}$. The main test variables were the material type of the pen-binder, the angle of the hook, and the confining reinforcement configuration.The test results indicate that adding pen-binders can effectively improve the strength and ductility of the column specimens confined with a non-code compliant confining reinforcement.
\end{abstract}

Keywords: column; confinement; hook; non-compliance; pen-binder.

\section{Introduction}

Some parts of Indonesia are located in regions with high seismic risk. In such regions it is compulsory to build structures that consistently meet the stringent requirements of earthquake resistant building construction. Consistent implementation of earthquake resistant design results in a structure that can survive a strong earthquake.

Received November $22^{\text {nd }}, 2011$, Revised July $24^{\text {th }}, 2011$, Accepted for publication August $24^{\text {th }}, 2012$. Copyright (C) 2012 Published by LPPM ITB \& PII, ISSN: 1978-3051, DOI: 10.5614/itbj.eng.sci.2012.44.3.2 
One of the seismic provisions of the SNI 03-2847-02 code [1] requires that the reinforced-concrete columns of a structure are confined using a hoop reinforcement with a seismic hook $\left(135^{\circ}\right)$. Installation of this kind of confining reinforcement is very tedious, especially in the case of large-dimension columns commonly used for high-rise buildings, flyovers and bridges. Therefore, at construction sites the installation of this kind of confining reinforcement is sometimes simplified by using a confining reinforcement with a 90-degreehook or with a double $\mathrm{C}$ configuration. Some reports about earthquake induced structural damage in Indonesia show examples of building collapse caused by inappropriate installation of confining reinforcements in reinforced-concrete columns [2-4]. Furthermore, many research studies on reinforced-concrete columns using confining reinforcements with a 90-degreehook show that the opening of the hook initiates failure, leading to buckling of the outer longitudinal reinforcing bars, and results in poor seismic performance of the structure (Sheikh [5], Saatcioglu [6], Wehbe [7]).

For this reason, the use of confining reinforcements with a 90-degreehook or with a double $\mathrm{C}$ configuration is basically not recommended for reinforcedconcrete columns. Nevertheless, this non-code compliant confining reinforcement is widely applied in the field because of the ease of its placement. The research reported in this paper introduces a simple device called a "pen-binder" that can be attached to non-code compliant confining reinforcements at construction sites. This "pen-binder" is expected to improve the structural performance of non-code compliant confining reinforcements to be at least equal to that of compliant confining reinforcements.

\section{Confinement Reinforcement}

Transverse reinforcement specified in design codes for reinforced concrete beams and columns has three main functions. These are: (1) to prevent buckling of longitudinal reinforcing bars; (2) to provide shear resistance; (3) to confine the concrete core.

Confinement of reinforced concrete columns is intended to prevent the spall cover of a tied column from failing immediately because the strength of the core is enhanced by triaxial stresses resulting from the confining effect of the transverse or hoop reinforcement. As a result, the column can undergo large deformations, eventually reaching a second maximum load when the reinforcement yields. The provision of transverse or confining reinforcement in the current SNI/ACI code is based on the work of Richart [8], and is developed so that the compressive strength of the confined core of a column after cover spalling is equal to the compressive strength of the gross section of the column before cover spalling. 
Based on this concept, the total cross-sectional area of a rectangular confining reinforcement, $A_{s h}$, should not be less than that required by Eq. (1):

$$
A_{s h}=0.09 s h_{c} \frac{f c^{\prime}}{f_{y h}} \geq 0.3 s h_{c}\left[\frac{A_{g}}{A_{c h}}-1\right] \frac{f c^{\prime}}{f_{y h}}(1)
$$

where $s$ is center-to-center spacing, $h_{c}$ the cross-sectional dimension of the column core measured center to center from the outer legs of the confining reinforcement, $f_{y h}$ the specified yield strength of the confining reinforcement, $A_{g}$ the gross area of the concrete section, and $A_{c h}$ the cross-sectional area of the concrete core measured out to out of the confining reinforcement.

The effectiveness of the confining reinforcement primarily depends on the volume of the concrete that is confined and the resulting distribution of the confining pressure [9]. In a column element, the ductility of the column crosssection under flexure is strongly influenced by the level of axial load. The higher the axial load the greater the reduction in the level of ductility produced (Sheikh and Yeh [5], Paultre and Legeron [10]).

In order to function properly, the confining reinforcement should be tied with hooks that provide lateral support to the longitudinal reinforcement. The hooks should be anchored into the concrete core in order to satisfy the seismic hoop requirements. The Indonesian concrete code defines the seismic hook as a hook on a hoop (Detail A), crosstie (Detail B) or stirrup (Detail C), having a bend of no less than 135degrees at its ends (see Figure 1).

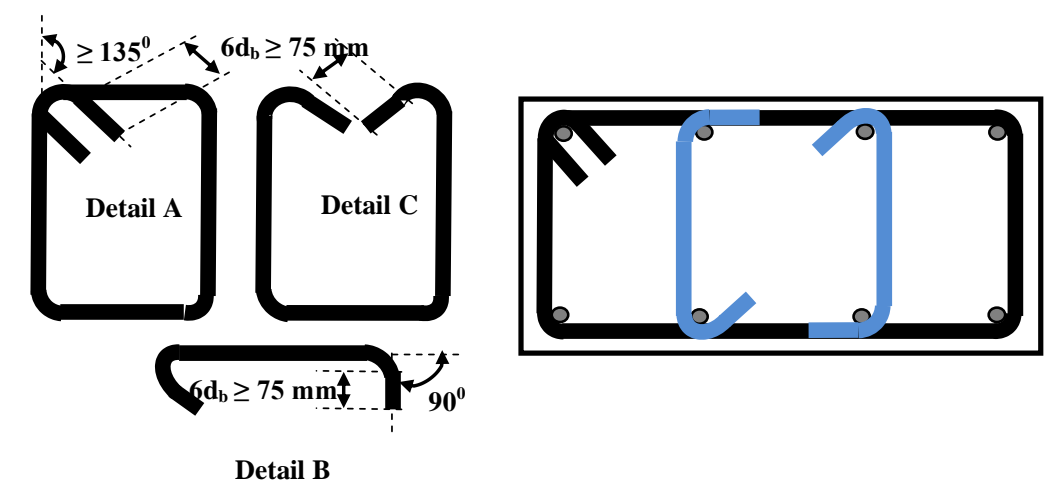

Figure 1 Seimic hook detailing.

The use of a confining reinforcement with a 90-degreehook is not recommended in the Indonesian concrete code, because this kind of confining reinforcement may result in poor seismic performance of the reinforced concrete columns. Previous researchers have shown that the failure of rectangular columns 
confined with a 90-degree hook reinforcement under cyclic load was initiated by the opening of the hook in the plastic hinge region. This was followed by buckling of the outer longitudinal rebar [7]. Lukkunaprasit and Sittipunt [11] have introduced a supplementary tie or hook-clips to prevent premature opening of a confining reinforcement with 90-degree hooks. They found that the clips can effectively hold the 90-degree hook ties after the loss of the concrete cover. However, according to Lukkunaprasit and Sittipunt, the use of these hook-clips can only be recommended for reinforced-concretecolumns in intermediate moment resisting frames.

\section{Confinement Model}

The influence of the tie arrangement on square columns was modeled for the first time by Sheikh and Uzumeri [12] using the "effectively confined core area" concept. Subsequently, this model was modified by Sheikh and Yeh [5] in order to incorporate the effects of eccentric loading. Later, a theoretical model was proposed by Mander [13], with a wider scope than the previously proposed models. His model also utilized the effectively confined core area concept. The maximum transverse pressure from the confining reinforcement can only be exerted effectively on that part of the concrete core where the confining stress has fully developed due to the arching action. The arching action is assumed to follow second-degree parabolas with an initial tangent slope of 45 degrees. Arching occurs vertically between layers of transverse reinforcement, and horizontally between tied longitudinal bars (Figure 2).

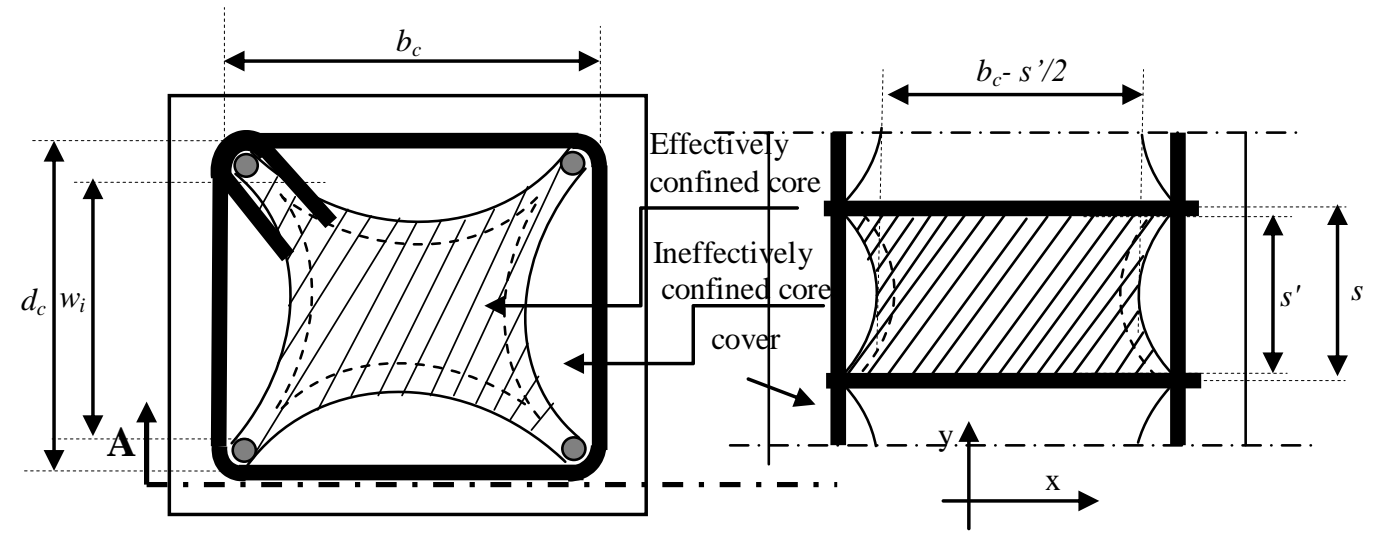

Figure 2 Effectively confined core for rectangular hoop reinforcement.

Midway between the levels of the confining reinforcement, the area of effectively confined concrete core $\left(A_{e}\right)$ is the smallest. 
The effectively confined concrete core area at hoop level is found by subtracting the area of the parabolas containing the ineffectively confined concrete. Incorporating the influence of the ineffective area in the elevation, the effectively confined concrete core area midway between the confining reinforcement levels [13] is

$$
A_{e}=\left(b_{c} d_{c}-\sum_{i=1}^{n} \frac{\left(w_{i}\right)^{2}}{6}\right)\left(1-\frac{s^{\prime}}{2 b_{c}}\right)\left(1-\frac{s^{\prime}}{2 d_{c}}\right)
$$

In order to allow for the fact that the effective confined core area is basically smaller than the core area, the effective lateral confining pressure acting uniformly at the core area can be considered as

$$
f_{l}^{\prime}=f_{l} k_{e}
$$

where $f_{l}$ is the lateral pressure mobilized by the confining reinforcement, assuming that the entire core area is effectively confined and $k_{e}$ is the confinement effectiveness coefficient, i.e.:

$$
k_{e}=\frac{A_{e}}{A_{c c}}=\frac{\left(1-\sum_{i=1}^{n} \frac{\left(w_{i}\right)^{2}}{6}\right)\left(1-\frac{s^{\prime}}{2 b_{c}}\right)\left(1-\frac{s^{\prime}}{2 d_{c}}\right)}{\left(1-\rho_{c c}\right)}
$$

$\rho_{\mathrm{cc}}$ is the ratio of the area of longitudinal reinforcement to the area of the core section. The lateral confining stresses $f_{l}$ is calculated as:

$$
f_{l}=\frac{A_{s}}{s . b_{c}} f_{y h}
$$

where $A_{s}$ is the total area of confining reinforcement, and $f_{\text {yh }}$ the yield strength of the confining reinforcement. For sections with equal confining pressure in two directions, the strength of the concrete is given by the following equation (Mander, [13]):

$$
f_{c c}^{\prime}=f_{c o}^{\prime}\left[-1.254+2.254 \sqrt{1+\frac{7.94 f_{l}^{\prime}}{f_{c o}^{\prime}}}-2 \frac{f_{l}^{\prime}}{f_{c o}^{\prime}}\right]
$$

where $f^{\prime}{ }_{c c}$ and $f^{\prime \prime}{ }_{c o}$ are the confined and unconfined strength of the concrete.

Subsequently, another model was proposed by Saatcioglu and Razvi [6], relating strength and deformability to lateral confining pressure. Their model is based on the computation of equivalent uniform confining pressure resulting from different confining reinforcement configurations. Passive confining pressure exerted by a square hoop depends on the restraining force developed in 
the confining reinforcement. The confining reinforcement can develop high restraining forces at the corners or hook ends, and a low restraining action in other locations. Figure 3 illustrates the build-up of passive confinement pressure in a square column. If crossties or internal confining reinforcements are used to support the intermediate longitudinal bars, additional points of high lateral restraint are generated.
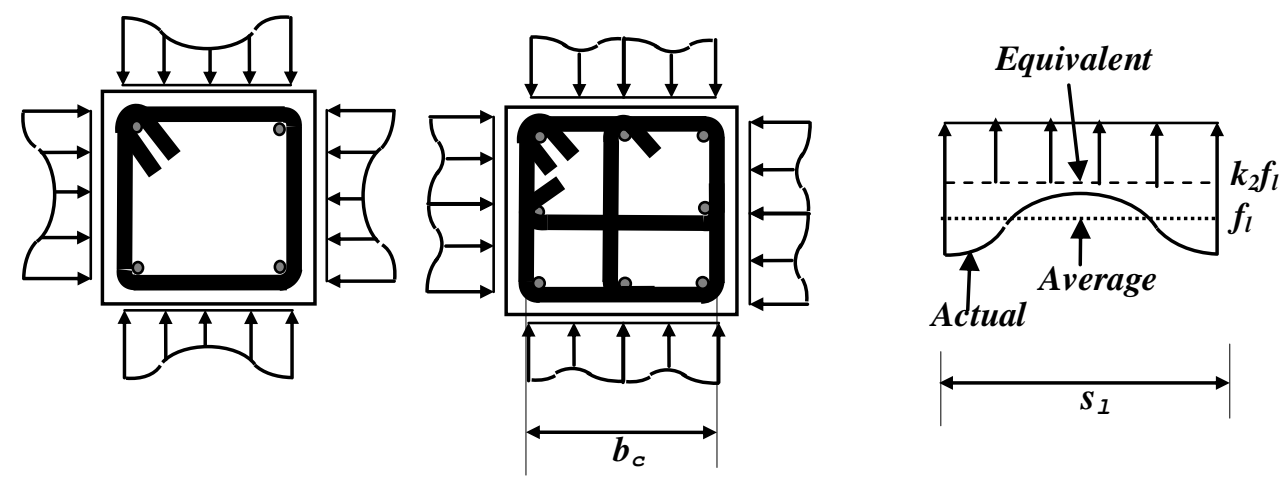

Figure 3 Lateral pressure in a square column [6].

The constitutive formulations of the Saatcioglu and Razvi [6] model can be described as follows:

$$
\begin{aligned}
& f_{c c}^{\prime}=f_{c o}^{\prime}+k_{1} f_{l e} \\
& f_{l e}=k_{2} f_{l} \\
& f_{l}=\frac{\sum A_{s} f_{y} h^{\sin \alpha}}{s b_{c}} \\
& k_{1}=6.7\left(f_{l e}\right)^{-0.17} \\
& k_{2}=0.26 \sqrt{\frac{b_{c}}{s} \frac{b_{c}}{s_{l}} \frac{1}{f_{l}}} \leq 1.0
\end{aligned}
$$

The equivalent uniform pressure $f_{l e}$ is derived from the average pressure $f_{l}$. The average pressure is the summation of transverse forces $A_{s} f_{y h}$ (area and yield strength of transverse reinforcement) divided by the area bound by the core dimensions, measured center to center of the perimeter hoop $\left(b_{c}\right)$ and center to center of the tie spacing $(s)$. Coefficient $k_{l}$ is obtained from a regression analysis of test data. Richart, et al. [8] reported that Eq. (7) with a constant value of 4.1 for $k_{l}$ produces a good correlation with spirally reinforced test cylinders. Their recommendations formed the basis for the confining reinforcement requirements of the ACI building code. For rectangular confining 
reinforcements the average pressure cannot reflect the true effect of the actual confinement pressure. In this case an equivalent uniform pressure is needed if Eq. (7) is to be used. The equivalent uniform pressure $f_{l e}$ used in Eq. (7) is often smaller than the average uniform pressure $f_{l}$, because of the non-uniformity of the lateral pressure. The reduction in pressure is reflected through coefficient $k_{2}$, which is a function of the tie spacing and the spacing of the laterally supported longitudinal reinforcement $s_{l}$.

\section{$4 \quad$ Experimental Program}

\subsection{Test Specimens}

In this study 18 column specimens were tested, $170 \mathrm{~mm}$ x $170 \mathrm{~mm}$ in crosssection and $480 \mathrm{~mm}$ in height. Figure $4 \mathrm{a}$ illustrates the test specimens and the pen-binder geometry. The test series reported here was designed to investigate three parameters influencing the behavior of the columns: the type of penbinder material used, the angle of the applied hook, and the confining reinforcement configuration. Two types of materials were used in this case, i.e.: steel and ABS (acrylonitrile butadiene styrene) plastic. The use of a plastic material for the pen-binder is to avoid corrosion of the material due to the inadequacy of the concrete to cover the pen-binder. The different confining reinforcement configurations used for the test are illustrated in Figure 5.

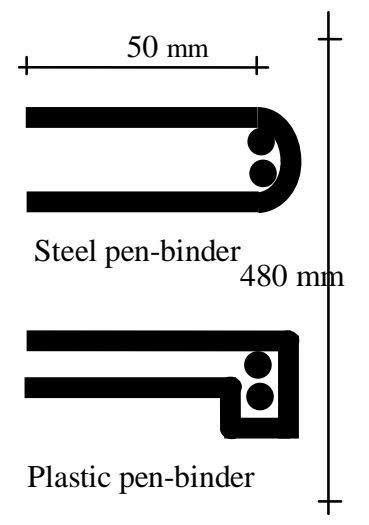

(a)

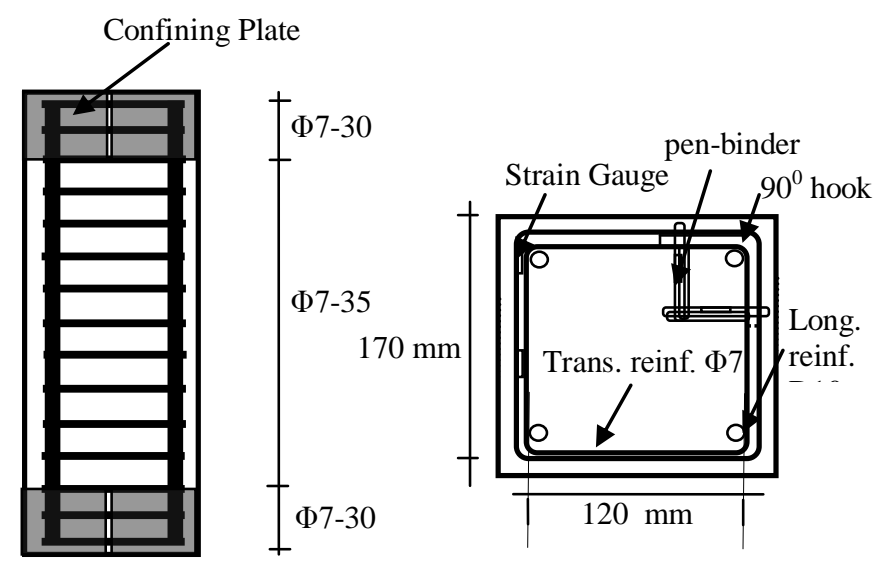

(b)

Figure 4 (a) Test specimen and pen-binder geometry; (b) strain gauge placement.

Configuration A is a concrete column without reinforcement; configuration B is a column with a code-compliant confining reinforcement; $\mathrm{C}$ and $\mathrm{D}$ have anon- 
code compliant confining reinforcement, without and with a pen-binder in a 90degree hook zone respectively; $\mathrm{E}$ and $\mathrm{F}$ are the same with a double $\mathrm{C}$ confining reinforcement with pen-binders, installed on two sides and on all sides of the confining reinforcement respectively. Double $\mathrm{C}$ configurations of confining reinforcements are commonly used for large-size columns.

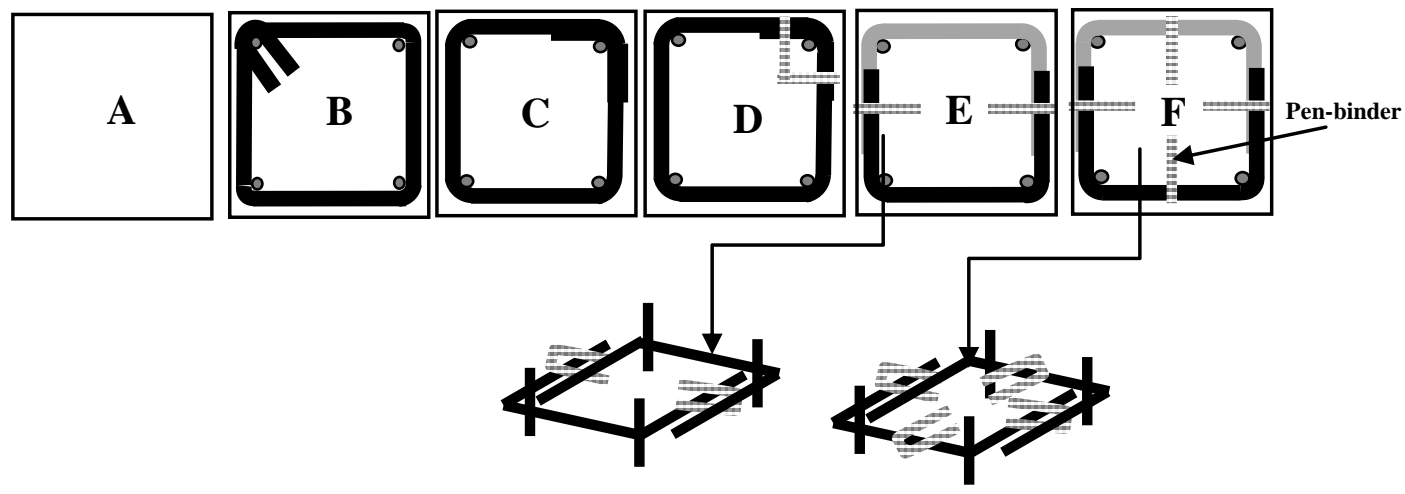

Figure 5 Confining reinforcement configurations.

The material properties, as determined by standard concrete cylinder tests and reinforcement coupon tests, are shown in Figure 6. A summary of all test specimens and their properties is provided in Table 1.

Table 1 Details of test specimens.

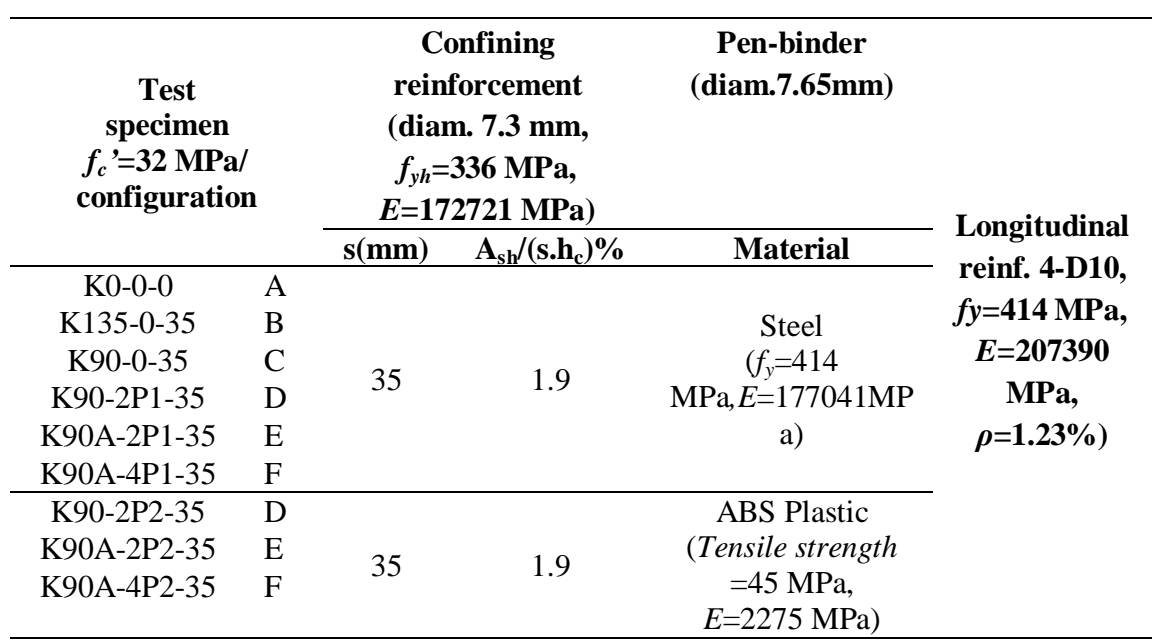




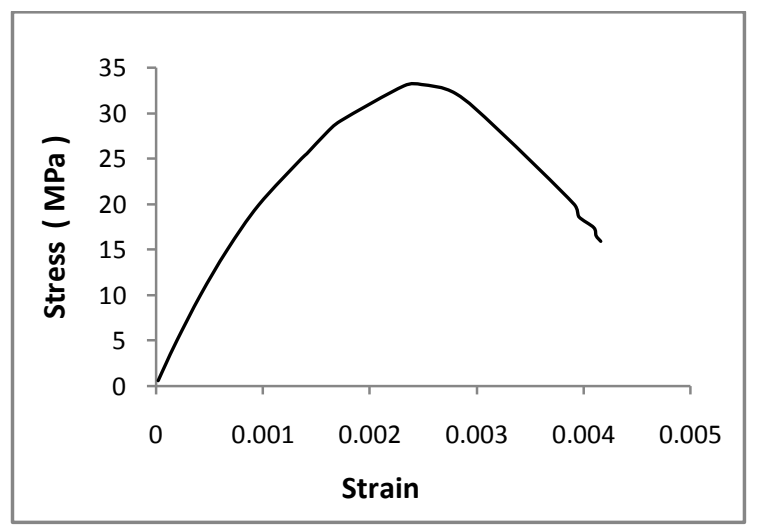

(a)

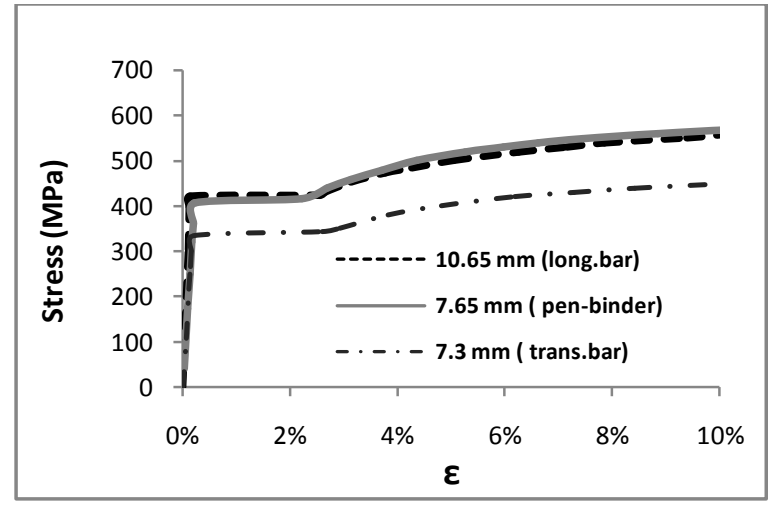

(b)

Figure 6 Stress-strain relationships for: (a) concrete cylinder tests, (b) penbinder and reinforcing bars.

\subsection{Test Setup}

The column specimens were tested using a Dartec compression testing machine with a $1500 \mathrm{kN}$ load capacity (Figure 7).

The specimens were externally confined in the top and bottom regions by steel brackets. Linear variable differential transducers (LVDTs) were placed on each column face to measure the axial deformations of the specimens. Strain in the confining reinforcement was measured using electric resistance strain gauges (Figure 4b). The specimens were loaded slowly. LVDTs were monitored throughout loading to insure concentric loading and the resulting data were recorded with a data logger. The loading was continued until a significant drop in load capacity was observed. 

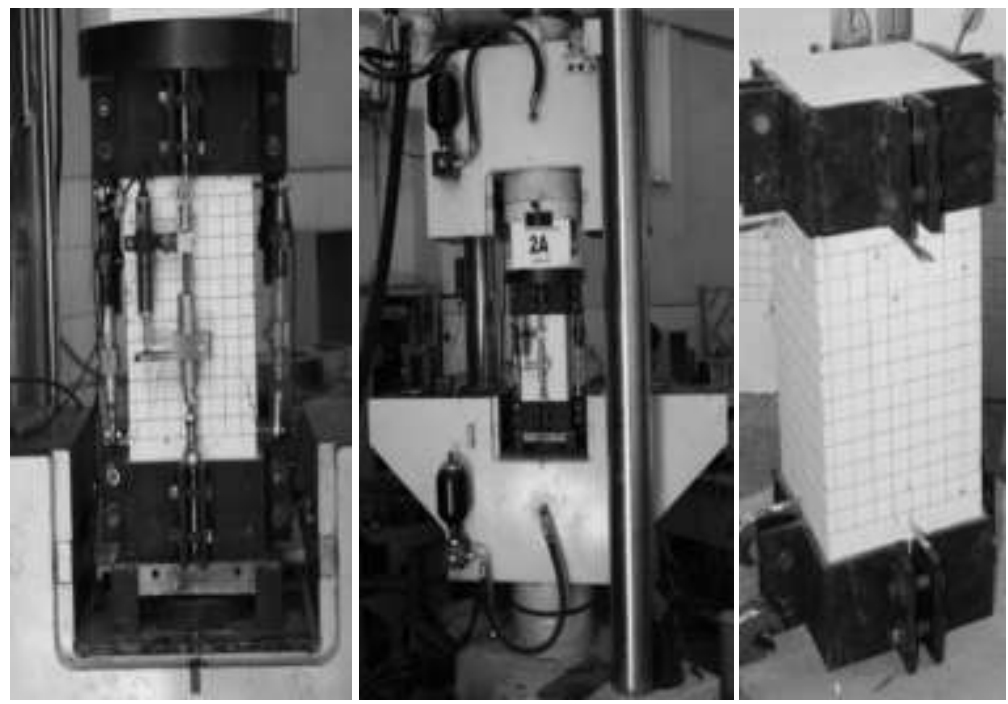

Figure 7 Specimen, test setup and compression testing machine.

\section{$5 \quad$ Test Results and Observed Behavior}

\section{$5.1 \quad$ Test Results}

All column specimens showed a similar response up to their peak loads. The first crack appeared on the column faces at a concrete strain of approximately 0.2 percent. The measured peak load and the corresponding axial strain varied depending on the confining reinforcement configuration and the type of penbinder material used (Figure 8). It can be noted that the columns with penbinders were still able to resist the peak load even after the concrete cover had spalled completely. At post-peak response, the load resistance of the tested column started to drop when bending and buckling of longitudinal reinforcement took place. A summary of the test results is presented in Table 2, which contains average values for two columns with identical test parameters.

The table includes computed and measured values determined as

$$
\begin{aligned}
& P_{0}=0.85 f_{c}^{\prime}\left(A_{g}-A_{s l}\right)+A_{s l} f_{y}(12) \\
& P_{0 . \text { core }}=0.85 f_{c}^{\prime}\left(A_{c h}-A_{s l}\right)(13)
\end{aligned}
$$

$P_{\text {test }}=$ measured peak axial load, $P_{c . \text { max }}=$ measured peak axial load carried by concrete $=P_{\text {test }}-A_{s l} f_{y}, A_{s l}=$ total area of longitudinal steel , $\varepsilon_{1}=$ minimum axial strain corresponding to the peak load resistance, $\varepsilon_{85}=$ axial strain corresponding to $85 \%$ of the peak load resistance on the falling branch of the load-strain 
relationship. Strength enhancement of the concrete core due to confinement is indicated in the table by the $P_{c \max } / P_{0 \text { core }}$ ratio. The ductility of the concrete is indicated in the same table by the $\varepsilon_{85} / \varepsilon_{1}$ ratio.

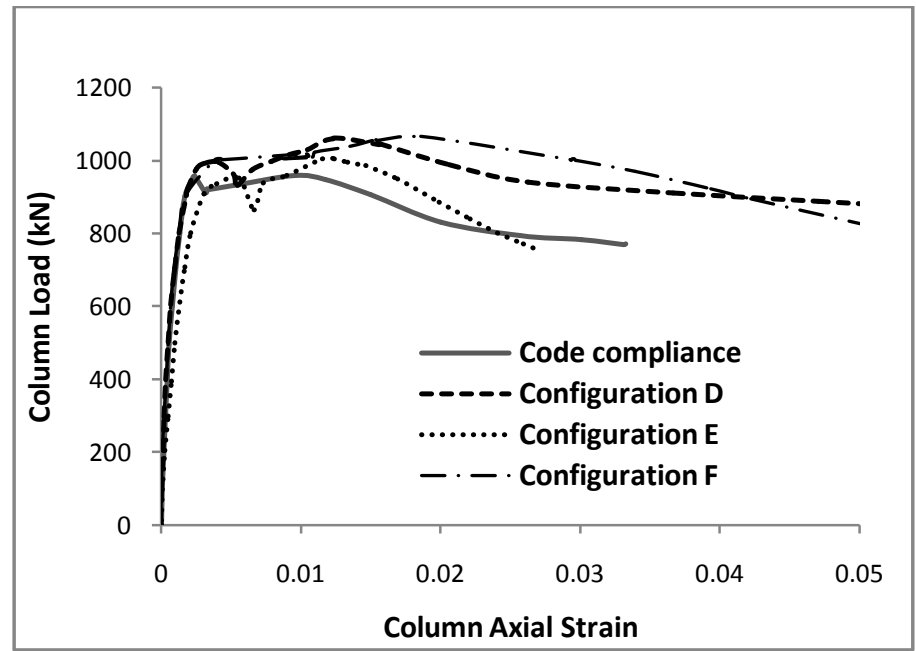

(a)

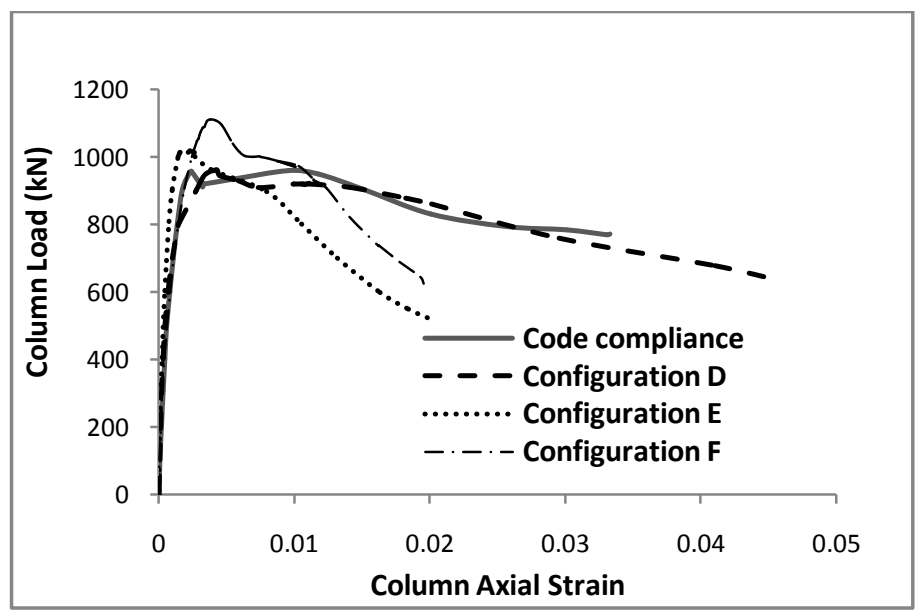

(b)

Figure 8 Axial load-strain relationship of average between two specimens with various confinement configurations, (a) steel pen-binder, (b) plastic pen-binder.

Table 2 shows that the pen-binders made of steel in configuration $\mathrm{D}$ and $\mathrm{F}$ are effective in increasing strength and ductility of reinforced concrete columns up to a significant deformation level. 
Table 2 Summary of test results.

\begin{tabular}{|c|c|c|c|c|c|c|c|c|c|}
\hline Specimen & $\frac{P_{o}}{(\mathbf{k N})}$ & $\frac{P_{\text {o.core }}}{(\mathbf{k N})}$ & $\begin{array}{l}P_{t e s t} \\
(\mathbf{k N})\end{array}$ & $\begin{array}{r}P_{c . \max } \\
(\mathbf{k N})\end{array}$ & $\begin{array}{c}P_{t e s t} / \\
P_{o}\end{array}$ & $\begin{array}{l}P_{\text {c.max }} / \\
P_{0 . c o r e}\end{array}$ & $\varepsilon_{1}$ & $\varepsilon_{85}$ & $\begin{array}{c}\varepsilon_{85} / \\
\varepsilon_{1}\end{array}$ \\
\hline K135-0-35 (B) & 923.90 & 444.56 & 960.24 & 812.72 & 1.04 & 1.83 & 0.002 & 0.0223 & 11.16 \\
\hline K90-0-35 (C) & 923.90 & 444.56 & 1013.07 & 865.55 & 1.10 & 1.95 & 0.0019 & 0.0093 & 4.94 \\
\hline K90-2P1-35(D) & 923.90 & 444.56 & 1061.28 & 913.77 & 1.15 & 2.06 & 0.0023 & 0.0409 & 17.81 \\
\hline K90A-2P1-35(E) & 923.90 & 444.56 & 1006.01 & 858.49 & 1.09 & 1.93 & 0.0029 & 0.0214 & 7.38 \\
\hline K90A-4P1-35(F) & 923.90 & 444.56 & 1066.05 & 918.53 & 1.15 & 2.07 & 0.0022 & 0.0411 & 18.69 \\
\hline K90-2P2-35(D) & 923.90 & 444.56 & 961.63 & 814.11 & 1.04 & 1.83 & 0.002 & 0.0242 & 12.15 \\
\hline K90A-2P2-35(E) & 923.90 & 444.56 & 1019.56 & 872.04 & 1.10 & 1.96 & 0.0012 & 0.0088 & 7.36 \\
\hline K90A-4P2-35(F) & 923.90 & 444.56 & 1111.18 & 963.66 & 1.20 & 2.17 & 0.002 & 0.0111 & 5.55 \\
\hline
\end{tabular}

\subsection{Pen-binder Configuration}

The steel pen-binders in the specimens with non-code compliant confining reinforcement were able to prevent the hook from opening. Steel pen-binders in configuration $\mathrm{D}, \mathrm{E}$ and $\mathrm{F}$ respectively were more effective in enhancing strength than those in configuration B (code compliant). Although it exhibits an increase in strength, the response of the column with configuration $\mathrm{E}$ in the high deformation range was not as good as that observed in the column with a codecompliant confining reinforcement (Figure 8). The specimen with configuration $\mathrm{F}$, which is simpler to install than configuration $\mathrm{D}$, showed the best inelastic response, as it was able to sustain higher deformations.

\subsection{Pen-Binder Material}

Generally, it was observed that pen-binders made of steel were more effective in improving strength and ductility of confined columns than pen-binders made of plastic (Figure 9).

Figure 9 shows that the configurations with a steel pen-binder gave a better performance than configurations with a plastic pen-binder. Only plastic penbinders with configuration $\mathrm{D}$ were found as effective as the column specimens confined with the code-compliant confining reinforcement. Figure 10 shows the test specimens after testing. Plastic pen-binders with configuration $\mathrm{E}$ failed to confine the concrete core effectively, as the confining reinforcement could not hold the expansion of the concrete core in the direction perpendicular to the pen-binder axis (Figure 10.c) 


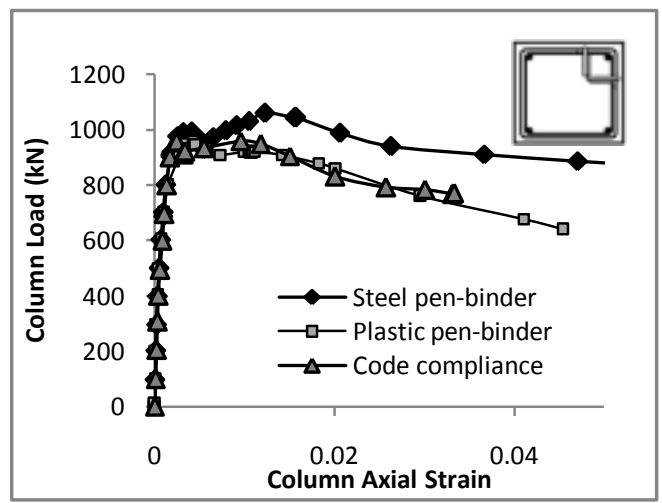

(a)

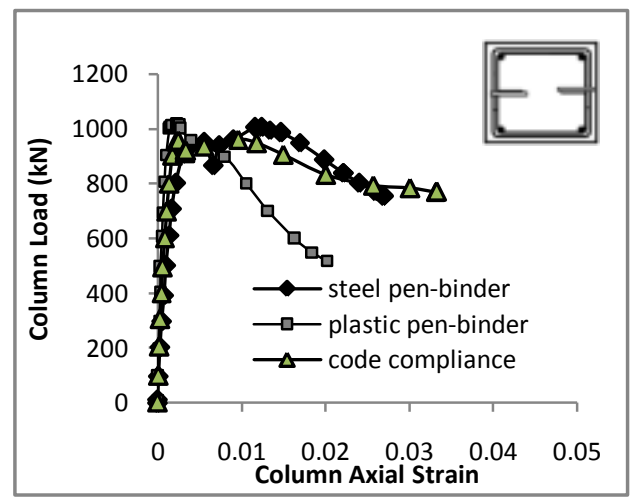

(b)

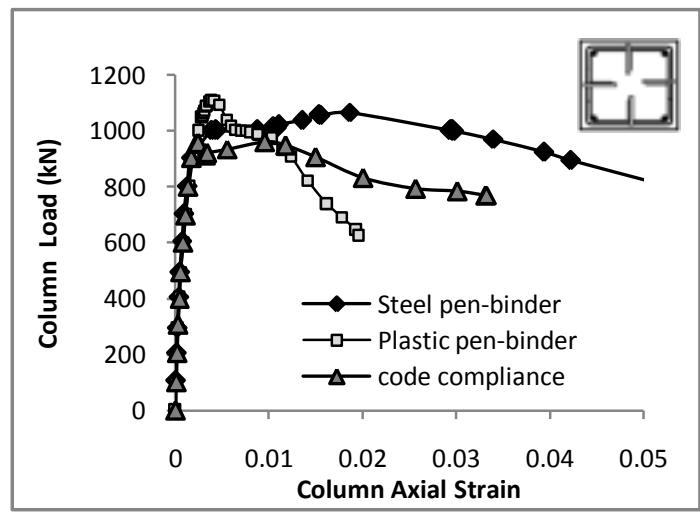

(c)

Figure 9 Comparison of axial load vs. axial strain for various configurations of column confinement and pen-binder materials: (a) configuration D, (b) configuration $\mathrm{E}$, (c) configuration $\mathrm{F}$.

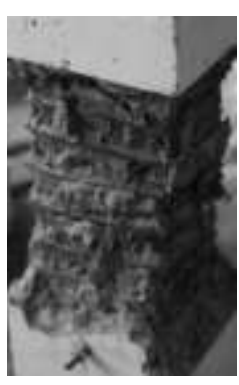

(a)

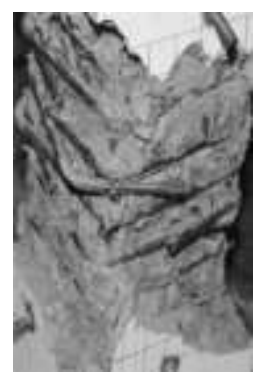

(b)

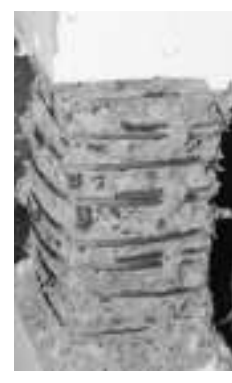

(c)

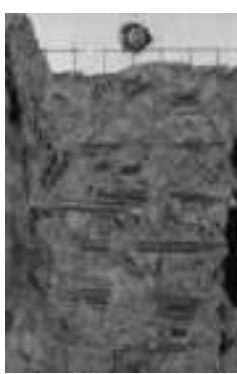

(d)

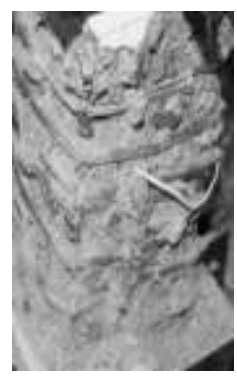

(e)

Figure 10 Test specimens after testing. (a) Configuration B, (b) configuration $\mathrm{C}$, (c) configuration D, (d) configuration E, and (e) configuration F. 


\subsection{Comparison of Analytical and Experimental Results}

Several investigators have previously presented analytical stress-strain relationships for concrete confined by transverse reinforcement. Among these, the relations suggested by Sheikh and Uzumeri [12], Mander [13] and Saatcioglu and Razvi [6] will be studied to determine their applicability in simulating the test columns with various configurations. Figure 11 shows a comparison of the experimental and analytical curves for the specimen with configuration B (code-compliant).

The model by Mander [13] and Sheikh Uzumeri [12] consistently overestimates the column axial stress capacities of the specimen with configuration B (Figure 11). The model by Saatcioglu and Razvi [6] gave better results than the other models; it can be seen that the model accurately predicts the peak stress and the deterioration rate.

Subsequently, the model by Saatcioglu and Razvi [6] was used to evaluate the confinement effectiveness of various pen-binder configurations. Confinement pressure along the side of the core for the various configurations can be determined by following the same procedure outlined previously.

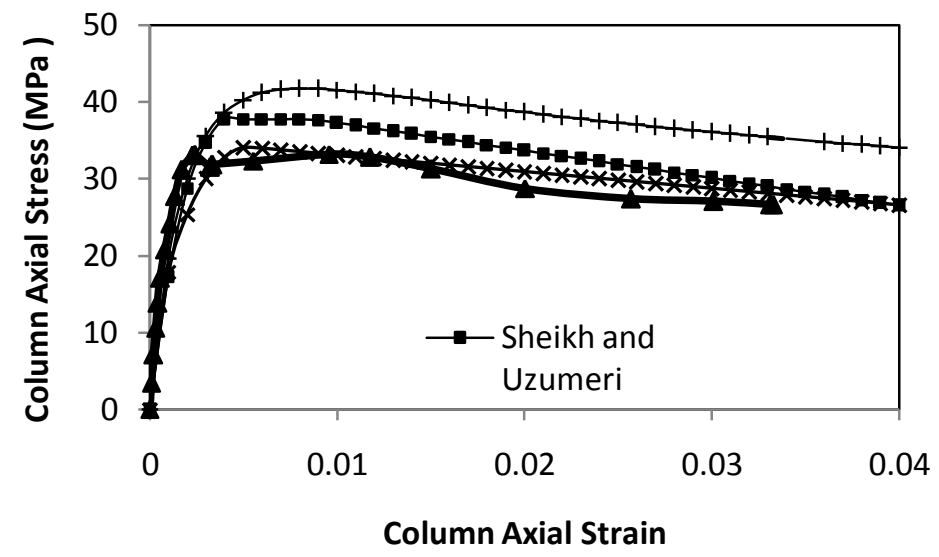

Figure 11 Comparison of experimental and analytical curves for a codecompliantspecimen.

The only difference is found in the value of $\mathrm{s}_{\mathrm{l}}$, therefore, in this analytical study the pen-binder is assumed to be effective in providing lateral restraint to the confining reinforcement. Because of this, each configuration will have different $\mathrm{k}_{2}$ values corresponding to the position of the pen-binders in the confining reinforcement. Coefficient $\mathrm{k}_{2}$ reflects the efficiency of the reinforcement 
arrangement and is equal to unity when the confining pressure is uniform as in the case of closely spaced circular spirals.

Figure 12 illustrates lateral pressure distributions along the sides of a rectangular column with various pen-binder positions. Equivalent lateral pressure $\mathrm{f}_{\mathrm{le}}$ acting perpendicular to the core dimensions can be computed using Eq. (8) and Eq. (9). A comparison of the analytical and the experimental strength values is presented in Table 3 . The results indicate good agreement between the analytical and the measured strength values.

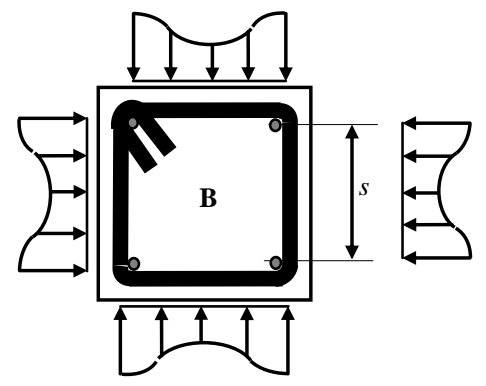

(a)

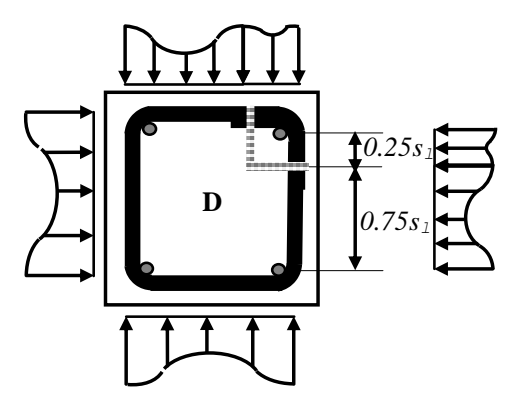

(c)

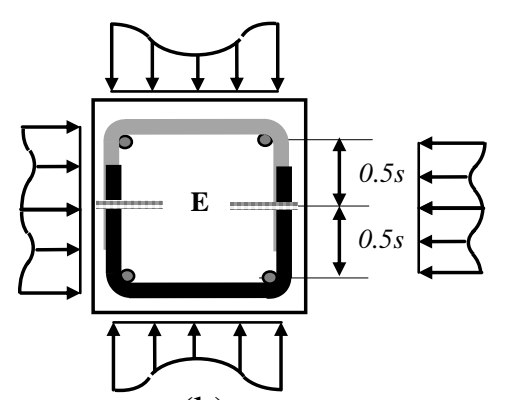

(b)
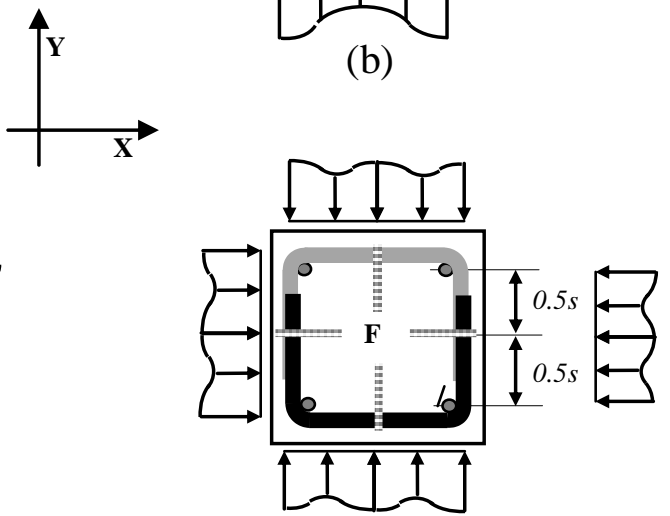

(d)

Figure 12 Distribution of lateral pressure for various configurations: (a) configuration $\mathrm{B}$, (b) configuration $\mathrm{E}$, (c) configuration $\mathrm{D}$, (d) configuration $\mathrm{F}$.

The $\mathrm{k}_{2}$ valuefor various configurations in Table 3 indicates that the steel penbinders in configurations $\mathrm{D}, \mathrm{E}$ and $\mathrm{F}$, respectively, are more effective in improving concrete strength than columns with a code-compliant confining reinforcement (configuration B).

Pen-binders with configurations D, E and F improve efficiency $28,6 \%, 20.7 \%$ and $41.3 \%$, respectively, compared with a code-compliant configuration. Configuration E showed the lowest improvement because the distribution of 
lateral pressure in the direction perpendicular to the pen-binder axis (axis $\mathrm{Y}$ ) has the same value as configuration $\mathrm{B}$. On the other hand configurations D and $\mathrm{F}$ improve efficiency in two orthogonal directions.

Table 3 Strength enhancement for various configurations.

\begin{tabular}{lcccccccc}
\hline $\begin{array}{c}\text { Column } \\
\text { Specimen }\end{array}$ & $\begin{array}{c}f_{\boldsymbol{l}} \\
(\mathbf{M P a})\end{array}$ & $\boldsymbol{k}_{\mathbf{2}}$ & $\boldsymbol{k}_{\boldsymbol{I}}$ & $\begin{array}{c}f_{\text {leff. }} \\
(\mathbf{M P a})\end{array}$ & $\begin{array}{c}f_{\text {co }} \\
(\mathbf{M P a})\end{array}$ & $\begin{array}{c}f_{\text {cc exp }} \\
(\mathbf{M P a})\end{array}$ & $\begin{array}{c}f_{\text {cc analytic }} \\
(\mathbf{M P a})\end{array}$ & $\begin{array}{c}f_{\text {cc analytid }} \\
\boldsymbol{f}_{\text {cc exp }}\end{array}$ \\
\hline $\begin{array}{l}\text { Configuration B } \\
\text { (code-compliant) }\end{array}$ & 6.313 & 0.213 & 6.371 & 1.344 & 27.2 & 33.2 & 35.76 & 1.08 \\
Configuration D & 6.313 & 0.274 & 6.103 & 1.732 & 27.2 & 36.72 & 37.74 & 1.03 \\
Configuration E & 6.313 & 0.257 & 6.171 & 1.623 & 27.2 & 34.81 & 37.21 & 1.07 \\
Configuration F & 6.313 & 0.301 & 6.007 & 1.901 & 27.2 & 36.88 & 38.62 & 1.05 \\
\hline
\end{tabular}

A stable confining reinforcement is essential to continuously provide effective confinement against the lateral expansion of the concrete beyond peak stress. Therefore the pen-binder plays an important role in holding the confining reinforcement, which will improve ductility significantly. The experimental results have been verified by comparing them with the stress-strain model of Saatcioglu and Razvi [6]. Figure 13 show a comparison of experimental and analytical curves for various configurations.

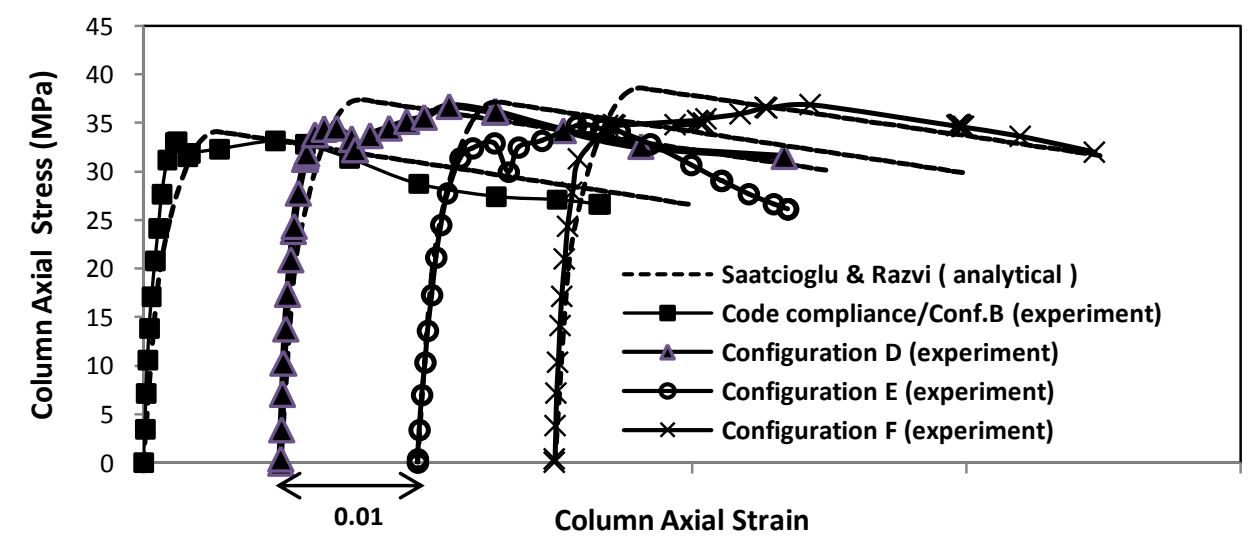

Figure 13 Comparison of experimental and analytical curves for various configurations.

All the specimens produced a performance similar to the Saatcioglu and Razvi model, except for the specimen with configuration E. The difference between the experimental curve and the analytical curve of configuration Eat a large axial strain was quite significant. The cause of this discrepancy may be that the model of Saatcioglu and Razvi [6] is based on the assumption that a codecompliant confining reinforcement is used, whereas configuration $\mathrm{E}$ is a column 
specimen with a double $\mathrm{C}$ confining reinforcement (non-code compliant) plus two pen-binders.

\section{Conclusions}

The following conclusions can be drawn from the results of the experimental investigation of short columns subjected to a pure axial load reported in this paper:

1. The use of pen-binders to hold a non-code compliant confining reinforcement improves strength and ductility of a concrete column very significantly. In general, the column specimens with a non-code compliant confining reinforcement plus pen-binders show better strength and ductility than column specimens with a code-compliant confining reinforcement.

2. From the various configurations studied, the configuration with an additional pen-binder at a 90-degree hook zone in anon-code compliant hoop reinforcement (i.e. configuration D) shows the most desirable performance up to a significant deformation level. Pen-binders made of steel were found to be more effective in improving strength and ductility of reinforced concrete column sections than pen-binders made of plastic.

3. The test results for various configurations have been verified extensively against analytical models and showed good correlations with the stressstrain model of Saatcioglu and Razvi [6]. With this finding, it can be said that the use of pen-binders can effectively provide lateral restraint to the confining reinforcement at the location where they are installed.

\section{Acknowledgements}

The research presented in this paper was supported by a grant from the Competitive Grant Program of the National Research Priority Based Batch 2 (2009) and the Doctoral Dissertation Research Grant for the Fiscal Year 2010, Directorate General of Higher Education, Indonesia.

\section{References}

[1] Purwono, R., Tavio, Imran, I. \& Raka, I.G.P., Tata Cara Perhitungan Struktur Beton Untuk Bangunan Gedung (SNI 03-2847-2002), ITS Press, Surabaya, Indonesia, 2006

[2] Imran, I., Suarjana, M., Hoedajanto, D., Soemardi, B. \& Abduh, M., Beberapa Pelajaran dari Gempa Yogyakarta; Tinjauan Kinerja Struktur Bangunan Gedung, Jurnal HAKI (ISSN No. 0216/5457), 7(1), pp. 1-13, 2006. 
[3] Imran, I., The 6 March 2007 West Sumatera Earthquake-Lesson Learned and Recommendations, The International Symposium on Disaster in Indonesia (ISDI): Problem and Solution, Padang, 26-28 Juli, 2007.

[4] Imran, I., Hoedajanto, D. \& Suharwanto, Beberapa Pelajaran dari Gempa Aceh; Tinjauan Kinerja Dua Bangunan Perkantoran di Banda Aceh, Prosiding Seminar Gempa HAKI 2005 (ISBN 979-98441-2-6), 25 Mei, Jakarta, 2005.

[5] Sheikh, S.A. \& Yeh, C., Tied Concrete Columns under Axial Load and Flexure, Journal of Structural Engineering, ASCE, 116(10), pp. 27802800, Oct. 1990.

[6] Saatcioglu, M. \& Razvi, S.R., Strength and Ductility of Confined Concrete, ASCE Journal of Structural Engineering, 118(6), pp. 15901607, June 1992.

[7] Wehbe, N.I., Saiidi, M.S. \& Sanders, D.H., Seismic Performance of Rectangular Bridge Columns with Moderate Confinement, ACI Structural Journal, 96(2), pp. 248-258, Mar.-Apr. 1999.

[8] Richart, et.al., The Failure of Plain and Spirally Reinforced Concrete in Compression, Bulletin No. 185, Univ. of Illinois Engrg. Experimental Station, Urbana, Ill,1929

[9] Sheikh, S.A. \& Khoury, S.S., A Performance Based Approach for The Design of Confining Steel In Tied Column, ACI Structural Journal, 94(4), pp. 421-431, Jul-Aug. 1997.

[10] Paultre, P. \& Legeron F, Confinement Reinforcement Design for Reinforced Concrete Columns, ASCE Journal of Structural Engineering, 134(5), pp. 738-749, May 2008.

[11] Lukkunaprasit, P.\& Sittipunt, C., Ductility Enhancement of Moderately Confined Concrete Tied Column with Hook Clips, ACI Structural Journal, 100(4), pp. 422-429, July-August 2003.

[12] Sheikh, S.A.\& Uzumeri, S.M., Strength and Ductility of Tied Concrete Column, Proceedings, ASCE, 106(5), pp. 1079-1102, May 1980.

[13] Mander, J.B., Priestley, M.J.N. \& Park, R., Theoritical Stress-Strain Model for Confined Concrete, ASCE Journal of Structural Engineering, 114(8), Aug. 1988. 